\title{
The effect of continuous venovenous hemofiltration on neutrophil gelatinase- associated lipocalin plasma levels in patients with septic acute kidney injury
}

Xingui Dai ${ }^{1,2+}, \mathrm{Tao}_{\mathrm{Li}^{2+}}$, Zhenhua Zeng ${ }^{1 \dagger}$, Chunlai $\mathrm{Fu}^{2}$, Shengbiao Wang ${ }^{2}$, Yeping Cai ${ }^{2}$ and Zhongqing Chen ${ }^{1 *}$

\begin{abstract}
Background: It is known that continuous venonenous hemofiltration $(\mathrm{CWH})$ does not affect the plasma level of neutrophil gelatinase-associated lipocalin (pNGAL) in acute kidney injury (AKI) patients. However, because of the unique pathophysiology underlying AKI caused by sepsis, the effect of CWH on pNGAL in this clinical setting is less certain. The purpose of this study was to determine the effect of CWH on pNGAL in sepsis-induced AKI patients.

Methods: Between August 1, 2014, and December 31, 2014, 42 patients with sepsis-induced AKI underwent CWH in the general intensive care unit of our institution and were consecutively enrolled in this study. Prefilter, postfilter, and ultrafiltrate pNGAL measurements were taken at the initiation of continuous renal replacement therapy (CRRT) and repeated after 2, 4, 8, and $12 \mathrm{~h}$ (T0, T2h, T4h, T8h, and T12h, respectively). The mass transfer, plasma clearance, and sieving coefficient were calculated based on the mass conservation principle.

Results: Following CWH initiation, we found that pNGAL in the ultrafiltrate decreased significantly $(P=0.013)$; however, levels at the inlet and outlet showed no significant change ( $P>0.05$ for both). Furthermore, there was no change in the total mass removal rate, total mass adsorption rate, and plasma clearance over time $(P>0.05$ for all), and a significant decrease in the sieving coefficient $(P=0.007)$ was seen.

Conclusions: The results of this study show a limited effect of CWH on pNGAL in sepsis-induced AKI patients. This suggests that pNGAL may be used as an indicator of renal progression in these patients. However, a larger study to confirm these findings is needed.
\end{abstract}

Trial registration: ClinicalTrials.gov, NCT02536027. Retrospectively registered on 20th August 2015.

Keywords: Acute kidney injury, Continuous venovenous hemofiltration, Neutrophil gelatinase-associated lipocalin, Sepsis

\section{Background}

Acute kidney injury (AKI) is a leading cause of sepsisrelated deaths in the intensive care unit (ICU), accounting for approximately half of all cases $[1,2]$. Early diagnosis of AKI and timely prediction of renal recovery are two of the primary challenges in the field of AKI research. On one hand, because serum creatinine ( $\mathrm{SCr}$ ) does not accurately

\footnotetext{
*Correspondence: zhongqingchen2008@163.com

${ }^{\dagger}$ Equal contributors

${ }^{1}$ Department of Critical Care Medicine, Nanfang Hospital, Southern Medical University, 1838 Guangzhou Avenue North, Guangzhou, Guangdong 510515, China

Full list of author information is available at the end of the article
}

reflect the glomerular filtration rate (GFR), it is considered a late marker for AKI $[3,4]$. On the other hand, the Beginning and Ending Supportive Therapy for the Kidney study suggested that a urine output $>500 \mathrm{~mL} / \mathrm{d}$ is the most important predictor of successful discontinuation of continuous venovenous hemofiltration $(\mathrm{CVVH})$. However, the urinary output is often affected by clinical interventions (e.g., diuretic administration) [5]. Therefore, it is of great importance to discover a reliable biomarker for the early diagnosis of AKI that reflects the renal function of patients when they are receiving $\mathrm{CVVH}$.

A growing body of evidence indicates that septic AKI is a different pathophysiological entity than other types 
of AKI. As such, the assessment and prognostic tools used to assess septic AKI need careful consideration, and this process has already started $[6,7]$. In the last decade, a number of novel biomarkers to help diagnose AKI at an early stage and accurately predict renal recovery have been studied intensively. Plasma neutrophil gelatinase-associated lipocalin (pNGAL), a $25 \mathrm{kDa}$ protein covalently bound to human neutrophil gelatinase, has been confirmed as a reliable biomarker for AKI occurrence and recovery from infectious disease [8-11]. However, patients requiring $\mathrm{CVVH}$ were excluded from most of these previous studies because it was thought that pNGAL concentration might change during $\mathrm{CVVH}$ through clearance as well as by release in the filter. A recent article by Schilder [12] reported that CVVH did not affect pNGAL in AKI patients due to low filter clearance. Another small series $(n=3)$ also reported that pNGAL was not significantly cleared during CVVH [13]. However, it remains unclear whether this also applies to septic AKI. The aim of the present study was to determine the effect of CVVH on NGAL concentrations in these patients.

\section{Methods}

\section{Participants}

The ethical committee of the First Peoples' Hospital approved this study, and it was registered with the US National Institutes of Health Clinical Trials Register (NCT02536027). Patients or their next of kin signed informed consent forms of their own accord after being fully informed of all the relevant details of the study. All patients with septic acute kidney injury (SAKI) undergoing $\mathrm{CVVH}$ in the general ICU were consecutively enrolled in the study during the period from August 1, 2014, to December 31, 2015.

\section{Inclusion and exclusion criteria}

Adult (>18 years) patients with SAKI undergoing continuous renal replacement therapy (CRRT) were assessed for inclusion. The urine output and $\mathrm{SCr}$ parameters were used from the 2012 Kidney Disease Improving Global Outcomes criteria [14], which were based on the Risk, Injury, Failure, Loss, End-stage/Acute Kidney Injury Network definitions. These included an absolute increase in $\mathrm{SCr}$ of $\geq 26.4 \mu \mathrm{mol} / \mathrm{L}$ over $48 \mathrm{~h}$, a percentage increase in $\mathrm{SCr}$ of $\geq 50 \%$ from baseline over the previous 7 days, or urine output $\leq 0.5 \mathrm{~mL} /(\mathrm{kg} \cdot \mathrm{h})$ for a period of $\geq 6 \mathrm{~h}$. Furthermore, based on the diagnostic criteria of the 2001 International Sepsis Definition Conference [15], sepsis was defined as a systemic, deleterious host response to infection resulting in a systemic inflammatory response syndrome characterized by two or more of the following (definitions in parentheses): hypothermia or fever (body temperature $<36{ }^{\circ} \mathrm{C}$ or $>38.5{ }^{\circ} \mathrm{C}$ ), tachycardia ( $>90$ beats/min), tachypnea
( $>20$ breaths/min or $\mathrm{PaCO}_{2}<32 \mathrm{~mm} \mathrm{Hg}$ on mechanical ventilation), leukocytosis $\left(>12,000 / \mathrm{mm}^{3}\right)$, leukopenia $\left(<4000 / \mathrm{mm}^{3}\right)$, or increased immature band forms $(>10 \%)$.

The following patients were excluded: (1) those with end-stage renal disease; (2) those with a history of renal transplant; (3) those with cancer; (4) those with acquired immunodeficiency syndrome; and (5) who had undergone high-dose steroid treatment.

\section{CRRT procedure}

CVVH was performed with a Fresenius 4008S CRRT plus machine (Fresenius Medical Care, Homburg, Germany) after establishing venous access in the femoral or jugular vein with an 11- to 14-Fr double-lumen catheter. The hemodiafilter membrane used was Fresenius AV600S (Fresenius, Homburg, Germany). In principle, patients were hemofiltered at a blood flow rate of 180-220 mL/ min in $2 \mathrm{~L}$ postdilution $\mathrm{CVVH}$ mode. An initial dose of heparin 400-1000 IU/h was given, with adjustment of the heparin infusion based on patient coagulation function. Anticoagulation also included a postfilter infusion of protamine, with a ratio of heparin $100 \mathrm{IU}$ to protamine $1 \mathrm{mg}$.

\section{Data collection}

Baseline patient data (age, gender, etiological factors, and underlying diseases) were collected on patient admission to the ICU. The white blood cell (WBC) count, $\mathrm{C}$-reactive protein (CRP), and procalcitonin (PCT) levels were obtained at CVVH initiation. Clinical data necessary to calculate sequential organ failure assessment (SOFA) and acute physiology and chronic health evaluation II (APACHE II) scores were also collected.

\section{Measurement of plasma NGAL}

Prefilter, postfilter, and ultrafiltrate samples were obtained at the beginning of CRRT and again after 2, 4, 8, and $12 \mathrm{~h}$ (T0, T2h, T4h, T8h, and T12h, respectively). The NGAL level was measured using an enzyme-linked immunosorbent assay (Lipocalin2/NGAL Duoset, DY1757, R\&D Systems, UK) with a measurable range of 20-3000 ng/mL.

\section{Calculation}

Based on the mass conservation principle, NGAL total mass removal rate (Mtr), mass adsorption rate (Mad), sieving coefficient (SC), and plasma clearance (PC) were calculated using the following formulas [12]:

$$
\begin{aligned}
& Q_{\mathrm{i}}=Q_{\mathrm{b}} \times(1-\text { Hct }) \\
& Q_{\mathrm{o}}=Q_{\mathrm{i}} \\
& M_{\mathrm{i}}=Q_{\mathrm{i}} \times C_{\mathrm{i}} \\
& M_{\mathrm{o}}=Q_{\mathrm{o}} \times C_{\mathrm{o}} \\
& M_{\mathrm{uf}}=Q_{\mathrm{uf}} \times C_{\mathrm{uf}}
\end{aligned}
$$




$$
\begin{aligned}
& M_{\mathrm{tr}}=M_{\mathrm{i}}-M_{\mathrm{o}} \\
& M_{\mathrm{ad}}=M_{\mathrm{tr}}-M_{\mathrm{uf}} \\
& \mathrm{PC}=M_{\mathrm{tr}} / C_{\mathrm{i}} \\
& \mathrm{SC}=2 \times C_{\mathrm{uf}} /\left(C+C_{\mathrm{o}}\right)
\end{aligned}
$$

Abbreviations:

$C_{\mathrm{i}}$ : Concentration in inlet plasma before addition of replacement fluid $(\mathrm{ng} / \mathrm{mL})$

$C_{\mathrm{o}}$ : Concentration in outlet plasma $(\mathrm{ng} / \mathrm{mL})$

$C_{\mathrm{uf}}$ : Concentration in the ultrafiltrate $(\mathrm{ng} / \mathrm{mL})$

$Q_{\mathrm{b}}$ : Inlet blood flow rate $(\mathrm{mL} / \mathrm{min})$

$Q_{\mathrm{i}}$ : Inlet plasma flow rate $(\mathrm{mL} / \mathrm{min})$

$Q_{\mathrm{o}}$ : Outlet plasma flow rate $(\mathrm{mL} / \mathrm{min})$

$Q_{\mathrm{uf}}$ : Ultrafiltration flow rate $(\mathrm{mL} / \mathrm{min})$

$M_{\mathrm{i}}$ : Mass inlet rate $(\mathrm{ng} / \mathrm{min})$

$M_{\mathrm{o}}$ : Mass outlet rate $(\mathrm{ng} / \mathrm{min})$

$M_{\mathrm{uf}}$ : Mass ultrafiltration rate (ng/min)

$M_{\mathrm{tr}}$ : Mass removal rate $(\mathrm{ng} / \mathrm{min})$

$M_{\text {ad: }}$ Mass adsorption rate $(\mathrm{ng} / \mathrm{min})$

RF: Replacement fluid flow rate (ng/min)

SC: Sieving coefficient

\section{Statistical analysis}

Continuous variable data with normal distributions were provided as mean \pm standard deviation (SD). Nonnormally distributed continuous variable data were presented as median (25th, 75th percentiles). The KruskalWallis test was used to compare measured and calculated data. Qualitative variable data were expressed as frequencies $(n)$ and percentages (\%). Statistical analyses were conducted using IBM SPSS 19.0 (SPSS; Chicago, IL, USA), and a $P$ value of $<0.05$ was considered statistically significant.

\section{Results}

Forty-eight consecutive subjects were screened. Of these, six subjects were excluded: three patients did not receive heparin anticoagulation due to severe coagulation disorders; one required an emergency operation due to active bleeding; one was excluded due to his next of kin withdrawing consent; and one patient died during CVVH, and his data were thus incomplete. Therefore, this study was completed for 42 patients, 24 males and 18 females, aged $53.2 \pm 17.3$ years. In 34 patients, venous access was established via the femoral vein, and in 8 patients, it was established via the jugular. Eighteen patients (42.9\%) died in the ICU. Nonsurvivors showed significantly higher median pNGAL at the inlet than survivors at T0 (1112 [323-1869] ng/mL versus 772 [121-1548] ng/mL, $P=0.033)$. Basic patient characteristics and clinical data at $\mathrm{T} 0$ are summarized in Tables 1 and 2, respectively.
Table 1 Clinical characteristics

\begin{tabular}{ll}
\hline Clinical characteristics & Patients with SAKI $(n=42)$ \\
\hline Age (year) & $53.2 \pm 17.3$ \\
Male gender $(n, \%)$ & $28(66.7)$ \\
Etiological factors $(n, \%)$ & \\
Abdominal infection & $18(42.9)$ \\
Pulmonary infection & $12(28.6)$ \\
Trauma-related infection & $10(23.8)$ \\
Urinary tract infection & $2(4.8)$ \\
Underlying diseases $(n, \%)$ & $16(38.1)$ \\
Hypertension & $10(23.8)$ \\
Diabetes & $8(19.0)$ \\
COPD & $6(14.3)$ \\
Coronary heart disease &
\end{tabular}

Normally distributed quantitative data are presented as mean \pm SD. Qualitative data are presented as $n$ (\%). SAKI septic acute kidney injury, COPD chronic obstructive pulmonary disease

All samples had detectable NGAL levels. Following initiation of CVVH, pNGAL in the ultrafiltrate decreased significantly $(P=0.013)$, whereas levels at the inlet and outlet did not change $(P>0.05$ for both; Fig. 1$)$. Furthermore, no change was seen in the total mass removal rate, total mass adsorption rate, and $\mathrm{PC}$ over time $(P>0.05$ for all), while the SC significantly decreased $(P=0.007$; Fig. 2$)$. Table 3 presents data for the total mass removal rate, mass adsorption rate, $\mathrm{SC}$, and $\mathrm{PC}$ of NGAL during CVVH.

Table 2 Biological data at T0

\begin{tabular}{ll}
\hline Biological data & Patients with SAKI $(n=42)$ \\
\hline MAP $(\mathrm{mm} \mathrm{Hg})$ & $67.2 \pm 32.5$ \\
$\mathrm{PaO}_{2} / \mathrm{FiO}_{2}$ & $192(131,352)$ \\
SOFA & $10 \pm 3$ \\
APACHE II & $18(14,21)$ \\
WBC count $\left(\times 10^{9} / \mathrm{L}\right)$ & $14.5(11.3,18.9)$ \\
$\mathrm{Hct}(\%)$ & $25.0 \pm 5.3$ \\
$\mathrm{PLT}\left(\times 10^{9} / \mathrm{L}\right)$ & $98(46,219)$ \\
$\mathrm{CRP}(\mathrm{mg} / \mathrm{dL})$ & $146.7(53.3,189.9)$ \\
$\mathrm{PCT}(\mathrm{ng} / \mathrm{mL})$ & $13.21(3.02,38.81)$ \\
SCr $(\mu \mathrm{mol} / \mathrm{L})$ & $242(189,367)$ \\
BUN $(\mathrm{mmol} / \mathrm{L})$ & $12.3 \pm 8.4$ \\
Fibrinogen $(\mathrm{g} / \mathrm{L})$ & $5.9 \pm 3.2$ \\
Albumin $(\mathrm{g} / \mathrm{L})$ & $28 \pm 7.5$ \\
Lactate $(\mathrm{mmol} / \mathrm{L})$ & $5.4(2.2,7.6)$ \\
\hline
\end{tabular}

Normally distributed quantitative data are presented as mean \pm SD. Non-normally distributed quantitative data are presented as median (25th, 75th percentiles). Qualitative data are presented as $n(\%)$. APACHE /I acute physiology and chronic health evaluation II, BUN blood urea nitrogen, COPD chronic obstructive pulmonary disease, CRP C-reactive protein, Hct hematocrit, MAP mean arterial pressure, $P C T$ procalcitonin, PLT platelets, SAKI septic acute kidney injury, SOFA sequential organ failure assessment, $\mathrm{SCr}$ serum creatinine, WBC white blood cell 


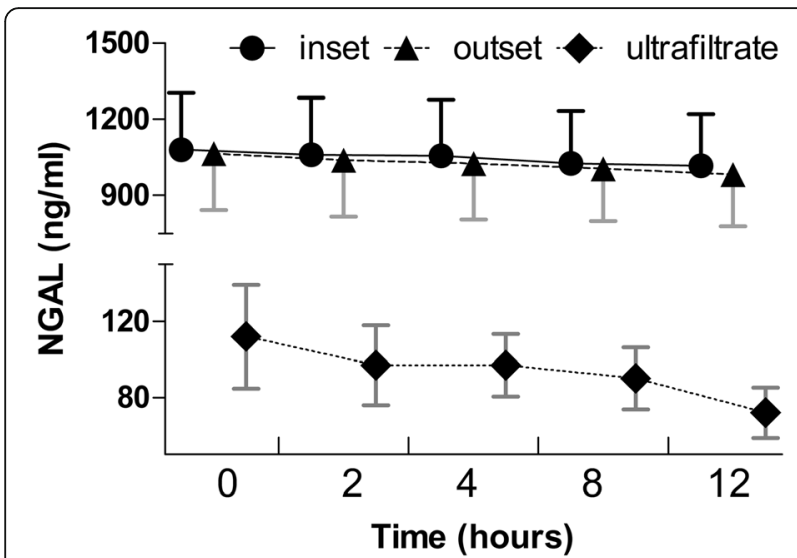

Fig. 1 Plasma NGAL concentration over time at the inlet and outlet, and in the ultrafiltrate, after the initiation of $\mathrm{CWH}$ in patients with SAKI. Levels of pNGAL at the inlet and outlet did not change $(P>0.05)$, whereas in the ultrafiltrate, the level decreased over time $(P=0.013)$. CWH, continuous venovenous hemofiltration; NGAL, neutrophil gelatinase-associated lipocalin; SAKI, septic acute kidney injury

\section{Discussion}

Results of this study demonstrate that CVVH did not significantly affect the plasma concentration of NGAL in patients with septic AKI: pNGAL did not decline, and NGAL clearance was lower than expected. There is considerable evidence that the underlying pathophysiology of septic AKI is unique in comparison with those of other types of AKI. Specifically, NGAL levels differ significantly between AKI patients with and without sepsis [16]. Therefore, it is reasonable to surmise that the clearance and production of NGAL during CVVH may be different than in other types of AKI. However, this study yielded results in accordance with the previous studies on AKI from other causes [12, 13]. A three-case study demonstrated that $\mathrm{CVVH}$ did not substantially affect pNGAL concentration in AKI patients [12]. Another study by Schilder and colleagues [13] also reported no net removal of NGAL during CVVH in patients with AKI. These findings indicate that CVVH does not affect the levels of NGAL in AKI patients with or without sepsis.

Contrary to the present study results, however, Donadio recently suggested that dialytic techniques and membranes can remove pNGAL and affect its accuracy as a biomarker of AKI [17]. They reported that low-flux dialysis (F8; Fresenius, Bad Homburg, Germany) did not remove pNGAL (which increased by $9.1 \pm 24.4 \%$, whereas high-flux dialysis (N190 FH; Nipro, Osaka, Japan; triacetate cellulose membrane, surface area $1.9 \mathrm{~m}^{2}$; ultrafiltration rate $8474 \mathrm{~mL} / \mathrm{h}$ per $100 \mathrm{~mm} \mathrm{Hg})$ decreased pNGAL significantly $(P<0.0001)$. What is more, they found that the reduction ratio of pNGAL with hemodiafiltration using a polyphenylene membrane (surface area $2.0 \mathrm{~m}^{2}$ ) and an ultrafiltration rate of $6800 \mathrm{~mL} / \mathrm{h}$ per $100 \mathrm{~mm} \mathrm{Hg}$ (Phylther; Bellco, Mirandola, Italy) or an acrylonitril and natrium metallylsulfone copolymer membrane (surface area $2.15 \mathrm{~m}^{2}$ ) and

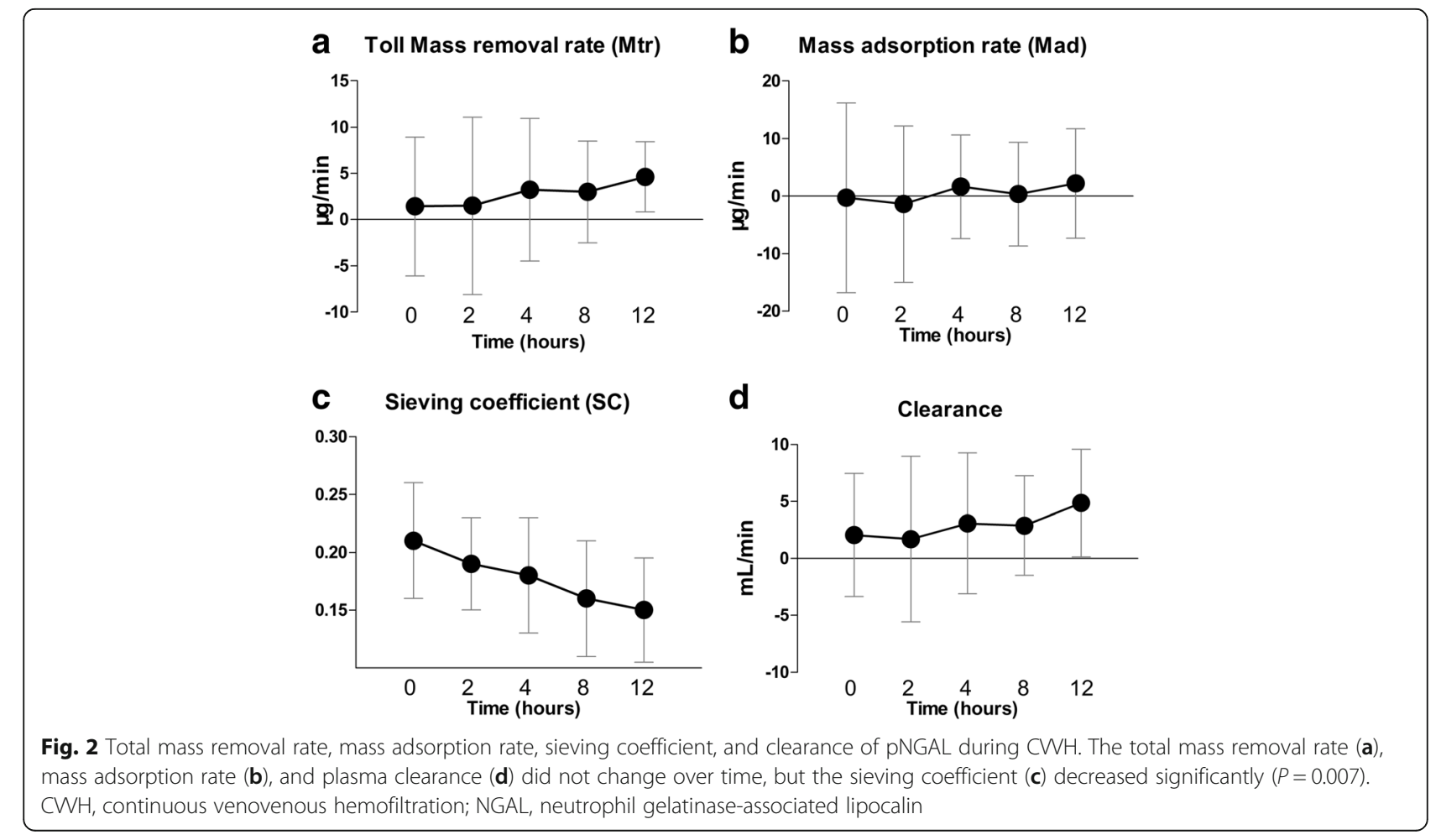


Table 3 Total mass removal rate, Mass adsorption rate, Sieving coefficient, and Plasma clearance of NGAL during CWH

\begin{tabular}{llllll}
\hline & T0 & T2 & $T 4$ & $T 8$ & $T 12$ \\
\hline$C_{\mathrm{i}}(\mathrm{ng} / \mathrm{mL})$ & $879(733,1466)$ & $850(685,1525)$ & $859(688,1496)$ & $847(689,1417)$ & $844(694,1405)$ \\
$C_{\mathrm{o}}(\mathrm{ng} / \mathrm{mL})$ & $867(697,1451)$ & $845(703,1332)$ & $890(661,1416)$ & $834(689,1326)$ & $819(646,1415)$ \\
$C_{\mathrm{uf}}(\mathrm{ng} / \mathrm{mL})$ & $32.2(26.7,40.8)$ & $30.3(23.6,34.9)$ & $27.7(24.1,31.9)$ & $26.1(21.2,30.1)$ & $24.0(20.1,28.0)$ \\
$M_{\mathrm{i}}(\mu \mathrm{g} / \mathrm{min})$ & $107(94,183)$ & $104(97,194)$ & $105(89,197)$ & $105(91,182)$ & $110(88,180)$ \\
$M_{\mathrm{o}}(\mu \mathrm{g} / \mathrm{min})$ & $104(92,181)$ & $107(88,170)$ & $109(85,182)$ & $107(89,170)$ & $109(85,172)$ \\
$M_{\text {uf }}(\mathrm{ng} / \mathrm{min})$ & $2189(1330,2748)$ & $1807(1181,3363)$ & $1888(1309,2312)$ & $2048(1129,3693)$ & $1397(1018,3471)$ \\
$M_{\mathrm{tr}}(\mathrm{ng} / \mathrm{min})$ & $1430(239,4914)$ & $1502(-2500,4801)$ & $3240(593,5544)$ & $3024(-82,5360)$ & $4620(2540,6687)$ \\
$M_{\text {ad }}(\mathrm{ng} / \mathrm{min})$ & $-313(-2576,3470)$ & $-1369(-5611,-1682)$ & $1651(-1494,3308)$ & $354(-2195,3201)$ & $2216(507,5104)$ \\
$\mathrm{SC}$ & $0.21(0.17,0.26)$ & $0.19(0.16,0.22)$ & $0.17(0.15,0.21)$ & $0.16(0.13,0.20)$ & $0.16(0.12,0.18)$ \\
Clearance & $2.05(0.39,3.57)$ & $1.45(-3.15,4.28)$ & $3.74(0.73,6.09)$ & $3.56(-0.45,5.80)$ & $4.57(1.85,8.94)$
\end{tabular}

Data are presented as median (25th, 75th percentiles). $C V V H$ continuous venovenous hemofiltration, NGAL neutrophil gelatinase-associated lipocalin, $C_{i}$ concentration in inlet plasma before addition of replacement fluid, $C_{\mathrm{o}}$ concentration in outlet plasma, $C_{\mathrm{uf}}$ concentration in the ultrafiltrate, $M_{\text {ad }}$ mass adsorption rate, $M_{\text {uf }}$ mass ultrafiltration rate, $M_{\mathrm{i}}$ mass inlet rate, $M_{\mathrm{o}}$ mass outlet rate, $M_{\mathrm{tr}}$ mass removal rate, $S C$ sieving coefficient

an ultrafiltration rate of $6500 \mathrm{~mL} / \mathrm{h}$ per $100 \mathrm{~mm} \mathrm{Hg}$ (Nephral 500; Gambro, Lund, Sweden) were higher than those seen with high-flux dialysis $(52.1 \pm 26.7 \%$ vs $26.6 \pm$ $26.1 \%, P=0.053)$. In the present study, CVVH treatments were performed using a polysulfone membrane (AV600s; Fresenius, Homburg, Germany; surface area of $\left.1.35 \mathrm{~m}^{2}\right)$, with a cutoff of approximately $30 \mathrm{kDa}$ and an ultrafiltration rate of $4000 \mathrm{~mL} / \mathrm{h}$ per $100 \mathrm{~mm} \mathrm{Hg}$. It is conceivable that membrane characteristics may impact NGAL removal significantly. In clinical practice, in view of different membrane characteristics among different CRRT machines, the result should be discriminatory. For example, the efficacy of NGAL removal using a AN69 membrane (M100 set; Prismaflex, Hechingen, Germany) with a surface area of $0.9 \mathrm{~m}^{2}$ may be lower than that using a highflux membrane. Therefore, further studies are needed to confirm whether the membrane type as well as the dialytic techniques used affect the clearance of NGAL in patients with septic AKI.

The present study had certain limitations. First, it was a single-center observational study with a small cohort of patients, which increased the chance of a type II error. A larger study is required to confirm the present finding. Second, the impact of anticoagulation was not considered. Schilder [12] reported that pNGAL was not affected by the anticoagulation of patients with AKI. However, another study demonstrated that sepsis was frequently associated with the pathological activation of the coagulation system [18]. Thus, it remains unclear whether or not pNGAL is affected by anticoagulation in patients with septic AKI receiving CVVH.

\section{Conclusions}

This study confirmed that pNGAL does not significantly decrease during CVVH in septic AKI. This means that the impact of $\mathrm{CVVH}$ does not need to be considered when pNGAL is used to judge renal progression in patients with septic AKI who are receiving CVVH.

\section{Abbreviations}

AKI: Acute kidney injury; APACHE II: Acute physiology and chronic health evaluation II; CRRT: Continuous renal replacement therapy; $\mathrm{CWH}$ : Continuous venovenous hemofiltration; ICU: Intensive care unit; NGAL: Neutrophil gelatinase-associated lipocalin; SOFA: Sequential organ failure assessment; UFR: Ultrafiltration rate

\section{Acknowledgements}

We thank the staff at the Department of Critical Care Medicine of the First Peoples' Hospital of Chenzhou for their assistance in this study.

\section{Funding}

The study was registered with the US National Institutes of Health Clinical Trials Register (NCT02536027). The work was supported by the National Natural Science Foundation of China (81500066), the Foundation of Health and Family Planning Commission of Hunan Province (B2016200) and the Foundation of Outstand Young of the First Peoples' Hospital of Chenzhou (N2015-003).

\section{Availability of data and materials}

All supporting data supporting for this study is found in the manuscript or is available upon request from the corresponding author, Zhongqing Chen.

\section{Authors' contributions}

$X D, L T$ and $Z Z$ designed and registered the study, participated in the data acquisition, and drafted the manuscript. CF carried out the biochemical assays and contributed to the analysis and drafted the manuscript. SW participated in the data acquisition and help with manuscript writing. YC participated in the data acquisition, and drafted the manuscript. ZC designed the study, guided the data analysis, responded for protocol revisions, and final draft revision. All authors read and approved the final manuscript.

\section{Competing interests}

The authors declare that they have no competing interests.

\section{Consent for publication}

Not applicable.

\section{Ethics approval and consent to participate}

The ethical committee of the First People's Hospital approved the study protocol, and the study was conducted in accordance with the principles contained in the Declaration of Helsinki. Written informed consent was given by all participants or their next of kin. 


\section{Author details}

'Department of Critical Care Medicine, Nanfang Hospital, Southern Medical University, 1838 Guangzhou Avenue North, Guangzhou, Guangdong 510515, China. ${ }^{2}$ Department of Critical Care Medicine, the First Peoples' Hospital of Chenzhou, Institute of Translation Medicine, 102 Luo Jia Jin Street,

Chenzhou, Hunan 423000, China.

Received: 18 May 2016 Accepted: 11 October 2016

\section{Published online: 19 October 2016}

\section{References}

1. Hoste EA, Lameire NH, Vanholder RC, Benoit DD, Decruyenaere JM, Colardyn FA. Acute renal failure in patients with sepsis in a surgical ICU: predictive factors, incidence, comorbidity, and outcome. J Am Soc Nephrol. 2003:14:1022-30

2. Uchino S, Kellum JA, Bellomo R, Doig GS, Morimatsu H, Morgera S, Schetz M, Tan I, Bouman C, Macedo $E$, et al. Acute renal failure in critically ill patients: a multinational, multicenter study. JAMA. 2005;294:813-18.

3. Shemesh $\mathrm{O}$, Golbetz H, Kriss JP, Myers BD. Limitations of creatinine as a filtration marker in glomerulopathic patients. Kidney Int. 1985;28:830-8.

4. Stevens LA, Coresh J, Greene T, Levey AS. Assessing kidney function-measured and estimated glomerular filtration rate. N Engl J Med. 2006:354:2473-83.

5. Uchino S, Bellomo R, Morimatsu H, Morgera S, Schetz M, Tan I, Bouman C, Macedo E, Gibney N, Tolwani A, et al. Discontinuation of continuous renal replacement therapy: a post hoc analysis of a prospective multicenter observational study. Crit Care Med. 2009;37:2576-82.

6. Zarbock A, Gomez H, Kellum JA. Sepsis-induced acute kidney injury revisited: pathophysiology, prevention and future therapies. Curr Opin Crit Care. 2014;20:588-95.

7. Gomez H, Ince C, De Backer D, Pickkers P, Payen D, Hotchkiss J, Kellum JA. A unified theory of sepsis-induced acute kidney injury: inflammation, microcirculatory dysfunction, bioenergetics, and the tubular cell adaptation to injury. Shock. 2014;41:3-11.

8. Kim H, Hur M, Cruz DN, Moon HW, Yun YM. Plasma neutrophil gelatinaseassociated lipocalin as a biomarker for acute kidney injury in critically ill patients with suspected sepsis. Clin Biochem. 2013;46:1414-8.

9. Dai X, Zeng Z, Fu C, Zhang S, Cai Y, Chen Z. Diagnostic value of neutrophil gelatinase-associated lipocalin, cystatin $C$, and soluble triggering receptor expressed on myeloid cells-1 in critically ill patients with sepsis-associated acute kidney injury. Crit Care. 2015;19:223.

10. Camou F, Oger S, Paroissin C, Guilhon E, Guisset O, Mourissoux G, Pouyes H, Lalanne T, Gabinski C. Plasma Neutrophil Gelatinase-Associated Lipocalin (NGAL) predicts acute kidney injury in septic shock at ICU admission. Ann Fr Anesth Reanim. 2013:32:157-64.

11. Srisawat N, Murugan R, Lee M, Kong L, Carter M, Angus DC, Kellum JA. Plasma neutrophil gelatinase-associated lipocalin predicts recovery from acute kidney injury following community-acquired pneumonia. Kidney Int. 2011;80:545-52

12. Schilder L, Nurmohamed SA, ter Wee PM, Paauw NJ, Girbes AR, Beishuizen A, Beelen $\mathrm{RH}$, Groeneveld AB. The plasma level and biomarker value of neutrophil gelatinase-associated lipocalin in critically ill patients with acute kidney injury are not affected by continuous venovenous hemofiltration and anticoagulation applied. Crit Care. 2014;18:R78.

13. de Geus HR, Betjes MG, Bakker J. Neutrophil gelatinase-associated lipocalin clearance during veno-venous continuous renal replacement therapy in critically ill patients. Intensive Care Med. 2010;36:2156-7.

14. Palevsky PM, Liu KD, Brophy PD, Chawla LS, Parikh CR, Thakar CV, Tolwani AJ, Waikar SS, Weisbord SD. KDOQI US commentary on the $2012 \mathrm{KDIGO}$ clinical practice guideline for acute kidney injury. Am J Kidney Dis. 2013;61:649-72.

15. Levy MM, Fink MP, Marshall JC, Abraham E, Angus D, Cook D, Cohen J, Opal SM, Vincent JL, Ramsay G. 2001 SCCM/ESICM/ACCP/ATS/SIS International Sepsis Definitions Conference. Crit Care Med. 2003;31:1250-6.

16. Vanmassenhove J, Glorieux G, Lameire N, Hoste E, Dhondt A, Vanholder R, Van Biesen W. Influence of severity of illness on neutrophil gelatinaseassociated lipocalin performance as a marker of acute kidney injury: a prospective cohort study of patients with sepsis. BMC Nephrol. 2015;16:18

17. Donadio C. Dialysis with high-flux membranes significantly affects plasma levels of neutrophil gelatinase-associated lipocalin. Crit Care. 2016;20:20.

18. Simmons J, Pittet JF. The coagulopathy of acute sepsis. Curr Opin Anaesthesiol. 2015:28:227-36.

\section{Submit your next manuscript to BioMed Central and we will help you at every step:}

- We accept pre-submission inquiries

- Our selector tool helps you to find the most relevant journal

- We provide round the clock customer support

- Convenient online submission

- Thorough peer review

- Inclusion in PubMed and all major indexing services

- Maximum visibility for your research

Submit your manuscript at www.biomedcentral.com/submit
) Biomed Central 